\title{
Optimization of the Laser/Cancer Treatment's Planning and Thermal Dosimetry Control
}

\author{
Mhamed Nour, Mohammed Bougataya, Karim El Guemhioui, Ahmed Lakhssassi \\ Université du Québec en Outaouais, Québec, Canada. \\ * Corresponding author. Email: noum03@uqo.ca \\ Manuscript submitted May 30, 2016; accepted October 23, 2016. \\ doi: 10.17706/ijbbb.2017.7.1.1-12
}

\begin{abstract}
During the laser thermal ablation process, it is challenging to control the side effects and optimize the planning of the dosimetry process for all patients. A software tool would help physicians plan and manage the dosimetry process while predicting and organizing the treatment. This would maximize the therapeutic effect and minimize any side effects, so new strategies can be proposed and evaluated.

In this paper, we propose a new dosimetry planning approach for the laser surgery/cancer treatment with physician interaction that takes into account all the steps of the management of the dosimetry process. Depending on the impact of the thermal damage to the tissue during the simulation, the software tool will output a dosimetry schedule for each simulation and keep all choices for a final decision.

Using Client Server technology, the software tool will also include a public and shared knowledge database to keep track of all simulations and learning process. This will optimize the process by dropping all unwanted simulation by delimiting the tissue tumor size, probe size, laser power, and time range.

A case study of the Laser Interstitial Thermal Therapy (LITT) will demonstrate the feasibility of the dosimetry framework. LITT can be a highly complex treatment, with many parameters influencing treatment efficacy.
\end{abstract}

Key words: Dosimetry, planning, bio-heat equation, laser source, thermal damage, tissue cancer, bioheat transfer simulation, side effects, database knowledge, intelligence artificial, client server technology, object-oriented programming.

\section{Introduction}

The objective of this paper is to provide an automatic dosimetry planning software tool which will help the physicians to go through the life cycle of the dosimetry planning process; and more specifically: Analysis of opportunities, Identification of aim, Exploration of options, Selection of the best one, Detailed planning, Plan evaluation, Plan Implementation, Closure of the Plan, and Feedback.

Expected results during the heating process are thermal distribution throughout the biological tissue and the estimation of the volume of tissues damaged during the treatment. The challenges are that the damaged tissues volume should be included within the tumor tissue volume and that there is a risk that the healthy tissue would be affected during the heating process. The calculation of the damaged tissues volume will be used to predict the impact on the tissue and calculate the number of visits needed during the dosimetry process. Furthermore, predicting the result of treatment depending on scenarios discussed between physicians and patients will improve the health care system by providing a personalized and focused treatment. 
Laser Interstitial Thermal Therapy (LITT) is a minimally invasive cytoreductive treatment. A low voltage laser is used to induce hyperthermia and kill tumor cells [1], [2]. A case study of the Laser Interstitial Thermal Therapy (LITT) [3]-[5] will demonstrate the feasibility of the framework. We will select a scenario of brain laser/cancer surgery treatment using solid state diode laser in the Nd:YAG range of $1064 \mathrm{~nm}$ and 12 Watt. This laser energy is transferred to the target tissue via a $\mathrm{CO} 2$ gas-cooled (Joule-Thomson effect) side-firing (directional) laser of $3.3 \mathrm{~mm}$ diameter. The heating temperature will be between $430 \mathrm{C}$ and 57 0C (the tissular necrosis state). The geometry will include two layered cylinders simulating the two tissues (healthy outside and tumor inside) with the probe located at the center of the tumor tissue. Many options exist [6] to model the laser power source: surface heat source or volumetric heat sources (Ray optics, Bear-Lambert law, Beam envelope method, Full wave). The framework will offer a selection of the source type which will be either a surface heat source a Beam envelope method.

Using the Multiphysics Simulation Tool COMSOL v5.2, we will build apps for physicians' use. Our COMSOL Multiphysics model is turned into an application with its own interface using the tools provided with the Application Builder desktop environment. Physicians will run the application remotely to study and choose the best scenario for their patients. This has already been done and the results presented in [7]. Using the oriented-object programming capabilities of MATTLAB and the MATTLAB connectivity with COMSOL, we will program the dosimetry software tool part.

\section{Framework for Planning the Laser Bio-heat Treatment}

In [7], we introduced a framework for the bio-heat transfer using laser as power source for cancer treatment. The physician will select a scenario describing tissue type, tissue tumor dimension, laser type, power and duration. The following outputs are available; real-time heat distribution and tissues damages. This paper is an extension of the work described in [7] and includes a dosimetry framework. Below, we describe a Dosimetry Framework with steps involved in the simulation of the surgery/laser treatment and a Dosimetry planning process:

\section{Step 1. Analysis of opportunities}

A lot of dosimetry tools exist and are documented in the literature. Each one of them is created for a specific objective, such as MRI dosimetry, Cancer Medicine online, Noise dosimetry, etc. but none for the Laser Interstitial Thermal Therapy (LITT).

This framework is specifically for Laser/Cancer treatment process from the first visit of the patient to the archiving of his file. Also the tool will help identify the risks and plan to neutralize it

We will consult many physicians in the domain to get their feedback in order to improve the model.

\section{Step 2. Identify aim}

The objective of the utilization of the framework should be clear and very well defined. The physician should read the document of the utilization of the Framework to make sure that the system will help for a specific and existing need. The physician will select an objective already defined on the menu before starting any simulation. This will help the physician to clarify the needs and to make sure the Framework is the software tool needed and that is can be used. Also, it is necessary to include the requirements to be verified by the physician prior to the utilization of the system.

\section{Step 3. Explore options}

For each patient, the physician will enter the patient's information in the Patient database. MRI pictures will also be included to help defining the geometry of the tumor tissue during the simulation.

Depending on the tissue type and the tumor size, the physician will explore options and define them. For instance variability of the power of the laser vs duration. The framework will help the physician explore the number of option, and simulate each one. 
For each option do the following:

\subsection{Dosimetry Plan}

The physician defines the dosimetry plan by selecting the tissue from the database, the tumor tissue size, the laser type, and the exposure duration.

The system will apply the environmental boundary conditions and the initial conditions.

The system will form the geometry, the mesh of the selected model and will select the thermal properties and optical properties of the tissues from a database.

The system takes the selected power deposition source selected and uses it.

\subsection{Temperatures Distribution Calculation}

Physiological Responses.

Output the simulation results: Temperature Distribution $\mathrm{T}(\mathrm{r}, \mathrm{t})$ and Tissue Damage $\Omega(\mathrm{r}, \mathrm{t})$

\subsection{Dosimetry Prediction}

The system will use the volume of damaged tissue to predict how many visits are needed to accomplish the laser therapy.

The physician will accept or reject the option. If accepted, the system will store it with other feasible options.

Step 4. Selection of best option

To select the best option, we need to include for each option a service cost that will include all the service charges. Then the system will run an operational research algorithm to select the optimal cost to serve the patient.

Step 5. Detailed planning

Now that we know the best option for both physician and patient, we need a detailed planning before starting the laser treatment. A detailed plan will include a visit schedule, and for each visit what has to be done (laser treatment at power $\mathrm{W}$ during Time $\mathrm{t}$ ) and the expected result (such as the percentage of the damage volume caused during the laser treatment).

Step 6. Plan implementation and evaluation

During each visit, the physician will mark the laser therapy as success if the damage predicted is equal to the result of the MRI. Else, he will need to correct the plan to adjust the damage prediction to the reality. If the plan is not successful, the system will adjust the plan according to a variation in term of percentage.

Step 7. Closure of the plan

At the end of the laser treatment, the physician will write the final state and result of the whole laser therapy and will close the patient file.

Step 8. Feedback

The physician will enter a feedback and notes that will help the software to adapt for next patient. To be able to include some sort of artificial intelligence, the system should learn from any simulation, any dosimetry and any patient plan so that some limitation will be included and errors implemented in the system to optimize the dosimetry process.

\section{Detailed Description of the Framework for Planning the Laser Bio-heat Treatment}

In the following, we describe the detailed procedure to be used.

\subsection{Software Tool Accessibility and Portability}

This is an extension of the work done in [7], Fig. 1 is the output of the Framework of the bio-heat transfer for Laser/Cancer treatment. We are proposing an extension to include the dosimetry process. The physician 
will use his laptop or smart phone to access the application.

\subsection{Patient Registration}

Fill out the patient form to complete patient registration process. MRI pictures can be scanned and included in the patient database; this should help defining the tumour tissue dimension. A module will be added later for this purpose.

\subsection{LITT Requirement}

Fill out the laser/cancer treatment questionnaire to go through the requirements before starting any laser/cancer treatment.

\subsection{Triggers Table}

We need to define some triggers that will optimize the simulation, for instance time should always be less than some time limit, power always less that some power limit, probe size limit, and if the temperature at far outline is greater than $500 \mathrm{C}$, the simulation should be stopped and an error message output. Physicians should able to add triggers to the system.

If the client exists in the patient database and the patient has passed the requirements, the physician will proceed to the following steps. \the whole process will be repeated for each patient.

\subsection{Temperature Distribution and Tissue Damage}

The physician will repeat the following steps for all laser/cancer treatment scenarios. Figure 1 shows the output of the software tool. The physician enters the parameters and select compute to execute the simulation in real-time).

If the client exists in the patient database and the patient has passed the requirements, the physician will proceed to the following steps. The whole process will be repeated for each patient.

Enter the following values: power, dimension, and time. Press Mesh, then press Compute (Fig. 1).

The software will output the temperature distribution, tissue damage, temperature $\mathrm{min} / \mathrm{max} /$ average and percentage damage volume at $\Omega=4.5$ ( $99 \%$ probability of dead tissue).

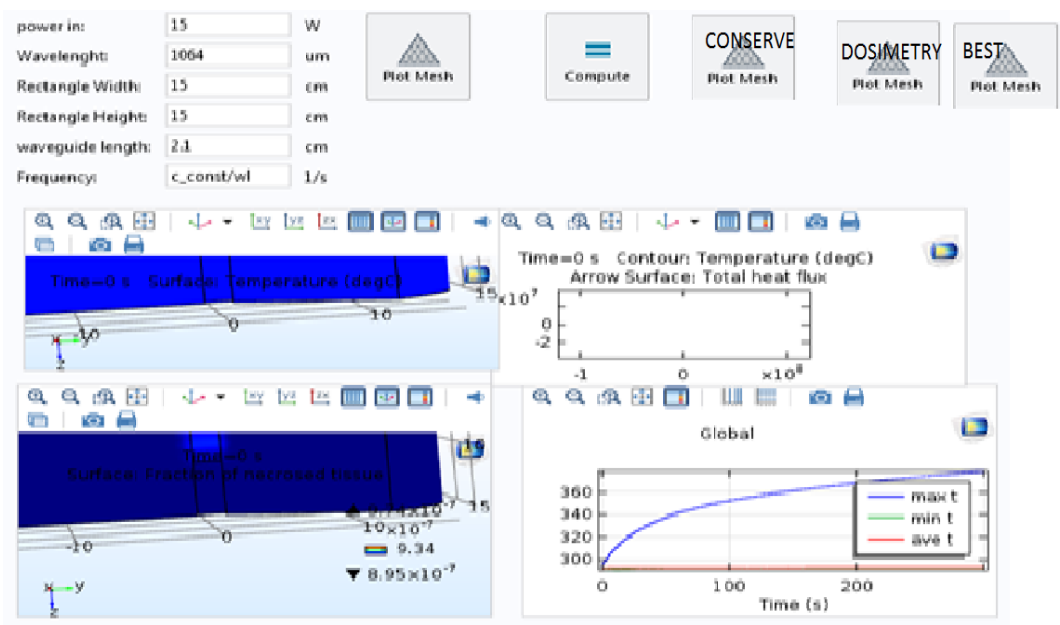

Fig. 1. The output of the software tool.

The physician enters the parameters and select compute to execute the simulation in real-time

1) Scenario generation

If the result of the scenario is acceptable, so the physician will press conserve this simulation in the simulation database (Fig. 1). 


\section{2) Accepted scenarios}

Select dosimetry, the software will output for each accepted simulation, a proposed dosimetry plan with the following information; number of visits, time, and power, cost of the visit and global cost. Table 2 shows the output of this step.

3) Dosimetry generation

At the end the scenario simulation process, the physician will enter the cost of laser treatment per second, then select dosimetry, the software will output for each accepted simulation, a proposed dosimetry plan with the following information; number of visits, time, power, and cost of the visit and global cost

4) Best dosimetry

When the physician will select the best button, the software will compare all the options and select the best one based on the criteria of selection, best cost, and minimum number of visits. Table 1 shows the output of this step.

Table 1. Best Cost Based on Minimum Total Cost

\begin{tabular}{|l|l|l|l|l|l|l|l|l|}
\hline $\begin{array}{l}\text { Power } \\
\text { in }(\mathrm{W})\end{array}$ & $\begin{array}{l}\text { Time } \\
(\mathrm{s})\end{array}$ & $\begin{array}{l}\text { Rect.Width( } \\
\mathrm{mm})\end{array}$ & $\begin{array}{l}\text { Rect.Height( } \\
\mathrm{mm})\end{array}$ & $\begin{array}{l}\text { Total } \\
\text { Vol }(\mathrm{mm} 2)\end{array}$ & $\begin{array}{l}\mathrm{A}=4.6 \% \mathrm{Da} \\
\mathrm{m} \text { vol mm2 }\end{array}$ & $\begin{array}{l}\text { Visit number } \\
\text { Cost per } \\
\text { visit }(\$)\end{array}$ & $\begin{array}{l}\text { Total } \\
\text { cost }(\$)\end{array}$ \\
\hline 15 & & & & & & & & \\
\hline
\end{tabular}

5) Schedule generation

If the proposed best dosimetry is accepted for a specified patient, the system will then create a calendar taking into account the laser unit, patient and health personal availability.

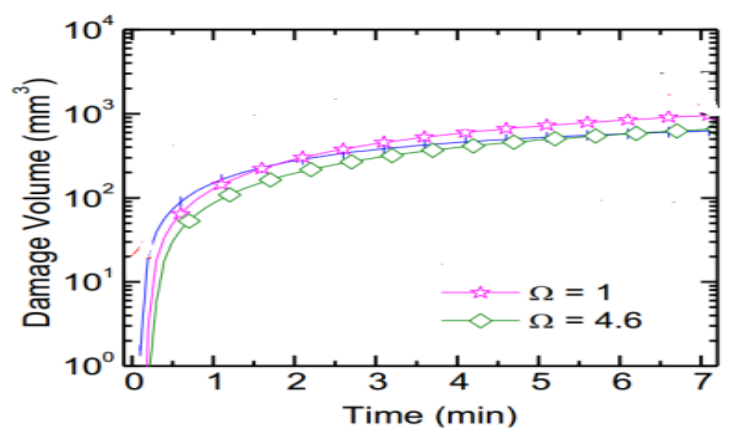

Fig. 2. The total volume of tissue necrosis using thermal damage integral and isothermal temperature.

Table 2. Global Dosimetry Proposed Plans, for Instance Cost Per Visit Equal Time [s] * Cost [\$]

\begin{tabular}{|c|c|c|c|c|c|c|c|c|}
\hline & & & & $\begin{array}{l}\text { Laser } \\
\text { utilization } \\
\text { cost }\end{array}$ & $25.00 \$$ & & & \\
\hline $\begin{array}{l}\text { Power in } \\
(\mathrm{W})\end{array}$ & Time (s) & $\begin{array}{l}\text { Cylinder } \\
\text { radius } \\
(\mathrm{cm})\end{array}$ & $\begin{array}{l}\text { Height } \\
(\mathrm{cm})\end{array}$ & $\begin{array}{ll}\text { Total } & \text { Vol } \\
(\mathrm{cm} 3) & \end{array}$ & $\begin{array}{l}\mathrm{A}=4.6 \% \\
\text { Dam vol } \\
\mathrm{cm} 3\end{array}$ & $\begin{array}{l}\text { Visit } \\
\text { number }\end{array}$ & $\begin{array}{l}\text { Cost per } \\
\text { visit (\$) }\end{array}$ & $\begin{array}{l}\text { Total cost } \\
\text { (\$) }\end{array}$ \\
\hline 10 & 10 & 2.53 & 2.53 & 50.85 & 5 & 10 & $250,00 \$$ & $2500,00 \$$ \\
\hline 10 & 15 & 2.53 & 2.53 & 50.85 & 6 & 8 & $375,00 \$$ & $3000,00 \$$ \\
\hline 10 & 20 & 2.53 & 2.53 & 50.85 & 8 & 6 & $500,00 \$$ & $3000,00 \$$ \\
\hline 10 & 25 & 2.53 & 2.53 & 50.85 & 10 & 5 & $625,00 \$$ & $3125,00 \$$ \\
\hline 15 & 10 & 2.53 & 2.53 & 50.85 & 12 & 4 & $250,00 \$$ & $1000,00 \$$ \\
\hline 15 & 15 & 2.53 & 2.53 & 50.85 & 15 & 3 & $375,00 \$$ & $1125,00 \$$ \\
\hline 15 & 20 & 2.53 & 2.53 & 50.85 & 17 & 2 & $500,00 \$$ & $1000,00 \$$ \\
\hline 15 & 25 & 2.53 & 2.53 & 50.85 & 19 & 2 & $625,00 \$$ & $1250,00 \$$ \\
\hline
\end{tabular}




\section{Dosimetry Plan and Model Simulation}

The physician will need to define a simulation plan, including laser type, tissue type and dimensions. As soon as the model will provide output, the physicians will analyse them, and adjust the therapy.

A cylinder of $2.54 \mathrm{~cm}$ radius by $2.54 \mathrm{~cm}$ thickness brian tissue, as shows in Fig. 1, is heated up to 10 seconds by a $5 \mathrm{~W}$ laser. The initial temperature of the brain tissues is considered as $293.15 \mathrm{~K}$. The tissue is modeled as a cylinder of radius rmat and height thickness, 3D, Bioheat Transfer (ht), Time dependent of range $(0,0.1,15)$ seconds. These values can be changed by the user of the model to simulate in real-time.

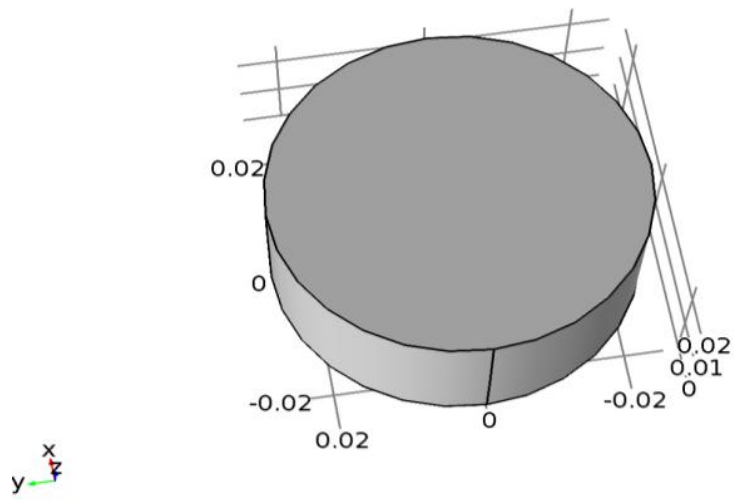

Fig. 3. A cylinder $2.54 \mathrm{~cm}$ radius by $2.54 \mathrm{~cm}$ thickness brian tissue is heated up to 10 seconds by a $5 \mathrm{~W}$ laser.

The physician will press Mesh and Press Compute (Fig. 1).

The software will output the temperature distribution, tissue damage, $\mathrm{min} / \mathrm{max} /$ average temperature and percentage damage volume at $\Omega=4.5$ ( $99 \%$ probability of dead tissue).

\subsection{Environmental Boundary Conditions and Initial Conditions.}

The model will take default values for initial conditions but will provide the possibility to update them if needed.

\subsection{Tissue Anatomy, Tissue Thermal Properties and Tissue Optical Properties}

As default dimension, the model will have a cylinder of $2.54 \mathrm{~cm}$ radius by $2.54 \mathrm{~cm}$ thickness of brian tissue, as shows in Fig. 3, it will be heated up to 10 seconds by a $5 \mathrm{~W}$ laser.

The Model will select the following thermal properties from the database depending on the selected tissue: Density $\rho$, Heat capacity at constant pressure, Heat capacity $\mathrm{Cp}$, Thermal Conductivity K, Density, blood $\rho_{\mathrm{b}}$, Specific heat, blood $\mathrm{Cb}$, Blood perfusion rate wb, Arterial blood temperature $\mathrm{Tb}$, and the Metabolic heat source Qmet.

There are a lot of tissues optical properties defined in the literature; Permittivity, Permeability, Electrical Conductivity, Absorption, Scattering, Anisotropy, Real Refractive Index. For our model we will use the following: Permittivity, Permeability $\mu$ and Electrical Conductivity. Table 3 shows the physical parameters used during the simulation.

The Permittivity is constant because the wavelength is constant in our case. The Permeability is equal to 1 since the tissue is non-magnetic material. Since there is no variation of the frequency, we will not use the dispersion models.

1) Power absorption tissue properties

We consider the following power absorption properties: Energy Absorption, Specific Absorption Rate (SAR), Frequency Factor and the Activation energy dE.

2) Power deposition models 
The laser beam [6] is modeled as a heat source in the plane with Gaussian profile gp1 (figure 4). This model uses the built-in Gaussian Pulse functions, which enforces that the integral under the curve equals unity. The emissivity of the surface of the brain tissue is approximately 0.8 . At the operating wavelength of the laser, it is assumed that absorptivity equals emissivity. The heat load due to the laser is multiplied by the emissivity.

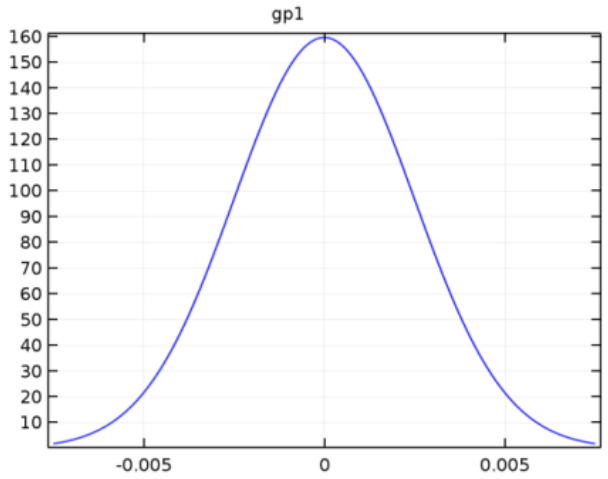

Fig. 4. The gaussian pulse with location 0 and standard deriation equal rspot.

The waveform function wv1 is a triangle with angular frequency and phase equal to 0 and the amplitude equal to1. We used from the COMSOL library, an analytic heat function hf defined as follows (Fig. 5):

$$
h f(x, y, t)=P_{\text {laser }} * g p 1(x-w v 1(t)) * g p 1(y)
$$

where $P_{\text {laser }}$ is the source power, gp1is Gaussian pulse function, wv1 is the waveform function.

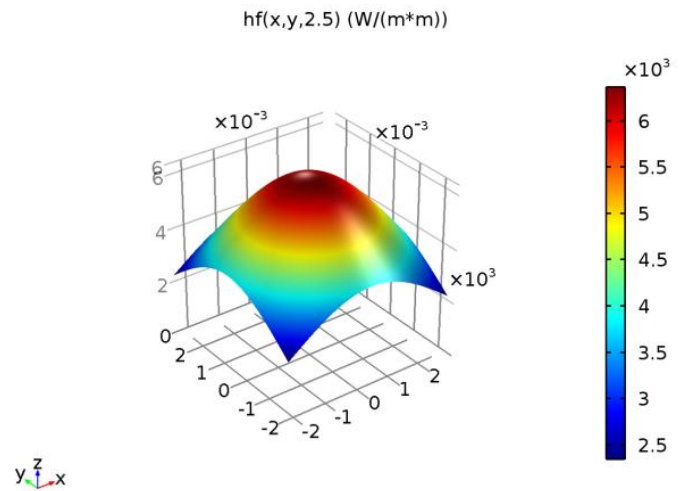

Fig. 5. Analytic heat function hf.

3) Temperature distribution and damage model

A parabolic heat equation based on Fourier's theory (FHE) has been used to mathematically model the temperature distribution of biological tissue during thermal ablation

We will start with the thermal conduction using Fourier's law for our first step of the simulation (results presented here) then upgrade to the modified Fourier's law and Relativist heat equation. We will then compare the results of these three simulations. Our model will offer the selection of any of these three mathematical models.

4) Parabolic heat equation based on Fourier's theory (FHE)

$$
\rho C_{p} \frac{\partial T}{\partial t}+\rho C_{p} \nabla T+\nabla \mathrm{q}=Q+Q_{\mathrm{bio}}
$$




$$
q=-k \nabla T
$$

where $T$ is the tissue temperature $(\mathrm{K}), C_{p}$ is the heat capacity $\left.\mathrm{J} /\left(\mathrm{kg}^{*} \mathrm{~K}\right)\right), \quad \rho$ is the density of the brain tissue $\left(\mathrm{kg} / \mathrm{m}^{\wedge} 3\right)$, and $\mathrm{k}$ is the thermal conductivity of brain tissue $\left(\mathrm{W} /\left(\mathrm{m}^{*} \mathrm{~K}\right)\right), Q$ is heat source, $Q_{b i o}$ is the perfusion and metabolic heat source.

5) The Perfusion Equation

$$
Q_{b i o}=\rho_{b} C_{b} \omega_{b}\left(T_{b}-T\right)+Q_{m e t}
$$

where $Q_{b i o}$ is the perfusion and metabolic heat source, $\rho_{\mathrm{b}}$ is the blood density, $C_{b}$ is Specific blood heat, $Q_{m e t}$ is Metabolic heat source, $\omega_{b}$ is Blood perfusion rate, $T_{b}$ is the blood flow rate, $T$ is tissue Temperature (K), $Q_{m e t}$ is the metabolic heat source.

Table 4. Settings of Qbio Parameters

\begin{tabular}{|l|l|}
\hline Description & Value \\
\hline Arterial blood temperature & $310.15[\mathrm{~K}]$ \\
\hline Specific heat, blood & $3650[\mathrm{~J} /(\mathrm{kg} * \mathrm{~K})]$ \\
\hline Blood perfusion rate & $0.866[\mathrm{l} / \mathrm{s}]$ \\
\hline Density, blood & $1035 \mathrm{~kg} / \mathrm{m}^{3}$ \\
\hline Metabolic heat source & 0 \\
\hline
\end{tabular}

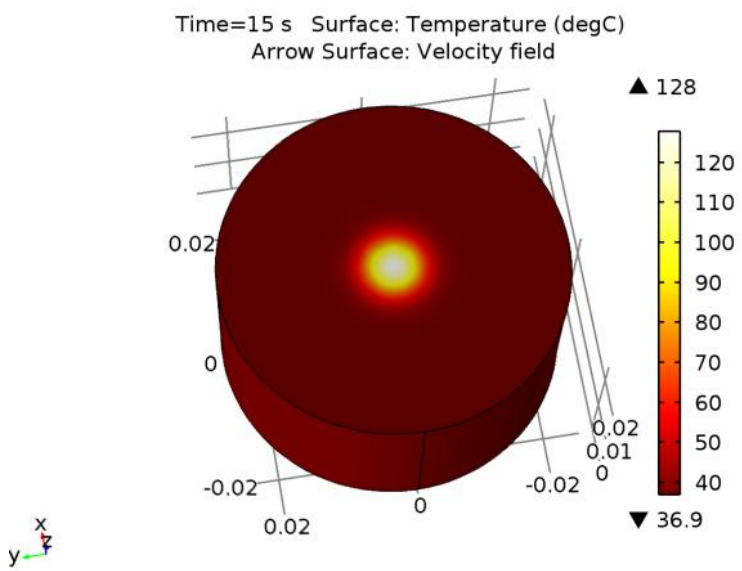

Fig. 6. Temperatre during 15 seconds at the surface of the brain tissue.

We consider that the metabolic heat and external heat sources are negligible with respect to the laser inducted heat. The initial temperature of the brain tissues was considered as $\mathrm{T} 0=293.15 \mathrm{~K}$.

6) Tissue temperature and tissue damage

Tissue temperature distribution.

The LITT of Brain Tumors was modeled by the bio-heat equation in a 3D geometric study, using electromagnetic module and the bio-heat transfer application mode with time dependent COMSOL 5.2.

7) Thermal damage

The induced damage (or damage integral) has been computed using well-established first order Arrhenius equation [8], [9]:

$$
\Omega(t)=\ln \frac{C_{0}}{C_{U D}(t)}=\int A \exp \left[-\frac{E_{a}}{R T(t)}\right] d t
$$

where $C_{0}$ is the original concentration of undamaged cells, $C_{U D}$ is the concentration of the remaining living cells after time t, the treatment time, $\mathrm{A}$ is the frequency factor, $E_{a}$ is the activation energy and $R$ is 
the universal gas constant. $(\mathrm{R}=8.314 \mathrm{~J} \mathrm{~mol}-1 \mathrm{~K}-1)$.

A damage integral of $\Omega=1$, corresponds to $63 \%$ percent probability of cell death, and damage integral of $\Omega=4.6$, corresponds to $99 \%$ percent probability of cell death at a specific point.

Figs. 6 to 8 show the heat distribution during the simulation which will help physicians to predict and organize the treatment.

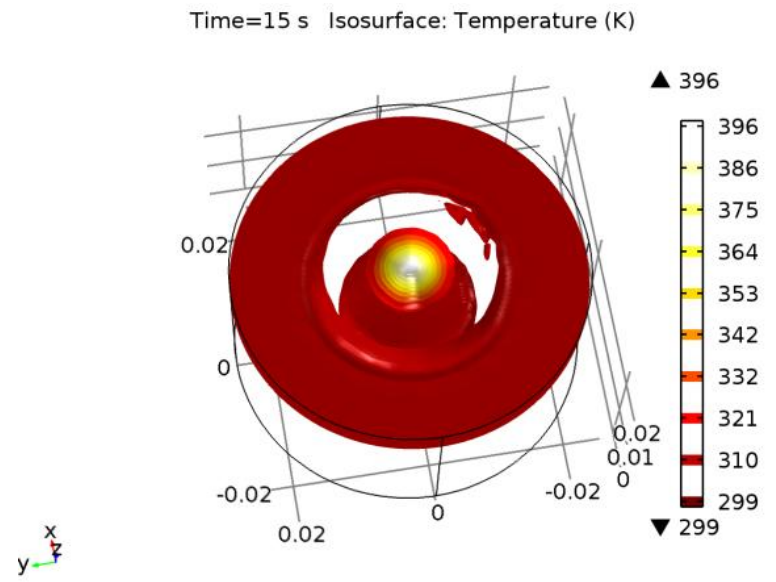

Fig. 7. Temperatre during 15 seconds at the surface of the brain tissue (Isothermal Contours (ht)).

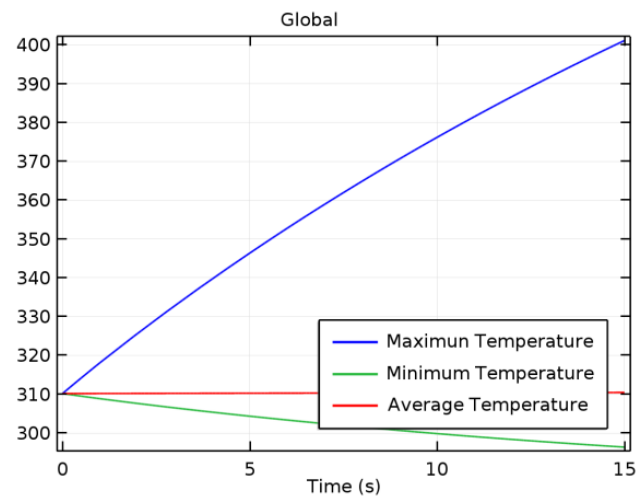

Fig. 8. Global max/min/average temperature (K) of the tissue during 15 seconds.

Such model shows also the impact of the thermal damaged tissues during the simulation.

Figs. 9 to 11 show the fraction of the necrotic tissue, the degree of tissue injury.

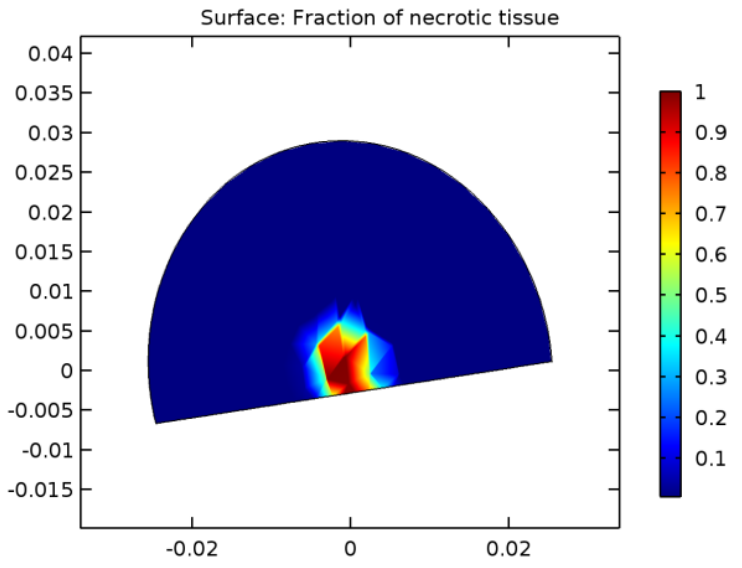

Fig. 9. 2D fraction of necrotic tissue. 


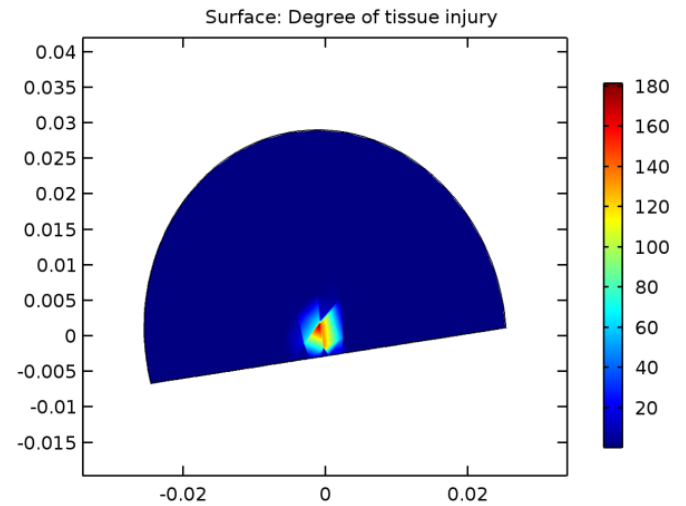

Fig. 10. 2D degree of tissue injury.

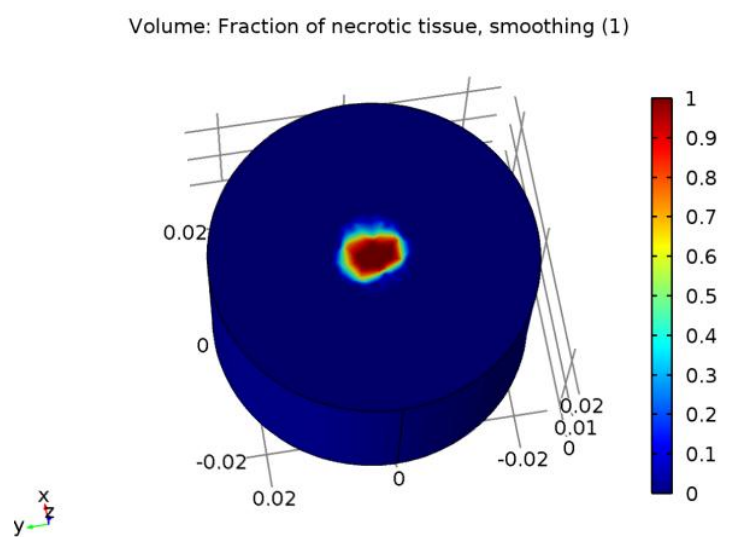

Fig. 11. Volume: Fraction of necrotic tissue, smoothing (1).

8) Thermal/Optical Properties dynamic update

Most models neglect the changes in the thermal and optical properties of the tissue during the temperature elevation, which makes these models unrealistic. We will introduce a mechanism to include these changes in the tissue properties during the treatment.

Table 3. The physical parameters used in our COMSOL numerical simulation. (Thermal Properties of Brain from [9])

\begin{tabular}{|c|c|c|c|}
\hline Name & Expression & Value & Description \\
\hline rmat & $1[\mathrm{in}]$ & $0.0254 \mathrm{~m}$ & material inner radius \\
\hline Thickness & $25400[\mathrm{um}]$ & $0.0254 \mathrm{~m}$ & mat inner thickness \\
\hline rspot & $8[\mathrm{~mm}]$ & $0.008 \mathrm{~m}$ & Radius of laser spot size \\
\hline plaser & $5[\mathrm{~W}]$ & $5 \mathrm{~W}$ & Laser power \\
\hline Period & $10[\mathrm{~s}]$ & $10 \mathrm{~s}$ & Time of laser to move back and forth \\
\hline Emissivity & 0.8 & 0.8 & surface emissivity of mat1 \\
\hline Temp & $310.15[\mathrm{~K}]$ & $310.15 \mathrm{~K}$ & Initial Temperature \\
\hline Heat Capacity & $3636\left[\mathrm{~J} /\left(\mathrm{kg} \mathrm{K}^{*}\right)\right]$ & $3636\left[\mathrm{~J} /\left(\mathrm{kg}^{*} \mathrm{~K}\right)\right]$ & Brain Heat Capacity \\
\hline Density & $1050\left[\mathrm{~kg} / \mathrm{m}^{\wedge} 3\right]$ & $1050\left[\mathrm{~kg} / \mathrm{m}^{\wedge} 3\right]$ & Brain Density \\
\hline Thermal conductivity & $0.51\left[\mathrm{~W} /\left(\mathrm{m}^{*} \mathrm{~K}\right)\right]$ & $0.51\left[\mathrm{~W} /\left(\mathrm{m}^{*} \mathrm{~K}\right)\right]$ & Brain Thermal conductivity \\
\hline A & & & Frequency factor \\
\hline $\mathrm{dE}$ & $7.39 \mathrm{e} 39[1 / \mathrm{s}]$ & $7.39 \mathrm{e} 39$ & Activation energy \\
\hline
\end{tabular}

\section{Conclusion}

Controlled thermal ablation presents a significant challenge during a laser surgery/cancer treatment. A 
tool to help physicians predict and organize the treatment will be helpful.

In this paper, we proposed an extension to the framework of the bio-heat transfer for laser/cancer treatment to include the management of the dosimetry process. A software tool will help physicians plan, update and report the dosimetry process of each patient.

Such model shows the impact of the heat distribution and thermal damage of the tissue during the simulation and outputs a detailed dosimetry plan.

A case study of LITT was proposed to demonstrate the utilization and the feasibility of the framework. The physicians selected a scenario with objective and the model output the predicted results which are thermal distribution throughout the biological tissues during the heating and the estimation of the volume of tissues damaged during the treatment. The physician may then adjust the scenario depending on the personalized and focused treatment.

\section{References}

[1] Tung, M. M., et al. (2008). Modeling the Heating of Biological Tissue Based on the Hyperbolic Heat Transfer Equation. Universidad Politecnica de Valencia, Valencia, Spain. Physics.med-ph.

[2] Laser Heating of a Silicon Wafer. Comsol Library.

[3] Alireza, M. M., \& Jason, L. S. (2014). Laser Interstitial Thermal Therapy in Treatment of Brain Tumors The NeuroBlate System. Informa, UK Ltd.

[4] Richard, T., \& Kurt, J. W. (2010). Laser surgery/cancer treatment: Real-time interactivity enhances interstitial brain tumor therapy. BioOptics World.

[5] Xin, C., \& Gerald, M. S. (2010). Modeling of laser coagulation of tissue with MRI temperature monitoring. Journal of Biomechanical Engineering.

[6] Comsol. Introduction to Comsol Multiphysics. 5.0 and Introduction to Application Builder, Comsol 5.1.

[7] Mhamed, N., Mohammed, B., Emmanuel, K., et al. (2016). Framework of the Bio-heat Transfer for a Lser/Cancer Treatment.

[8] Yassene, M., \& Janko, F. V. (2005). A finite element method to simulate laser interstitial thermos therapy in anatomical inhomogeneous regions. BioMedical Engineering OnLine. BioMed.

[9] Fujita, S., Tamazawa, M., \& Kuroda, K. (1998). Effects of blood perfusion rate on the optimization of RF-capacitive hyperthermia. IEEE Trans. Biomed. Eng., 45(9), pp 1182-1186.

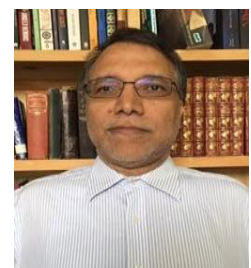

Mhamed Nour received a B.Ing. in computer science from INSAE, Rabat, Morocco in 1984, and a M.Sc.A in computer science in software engineering from Université du Montrèal (UdeM), Québec, Canada in 1994. He also did research on the distributed algorithms for multi-media routing with QoS constraints at CRIM (Centre de Recherche Informatique de Montreal) and UdeM. He is currently a PhD student at Université du Québec en Outaouis (UQO), Québec, Canada .

Mhamed taught computer science for more than 20 years and has been working as a senior network analyst since 1996. His research activities focus on the heat transfer mechanisms in biological tissues for thermal treatment practices and the development of algorithms for automatic bio dosimetry for tumour laser treatment.

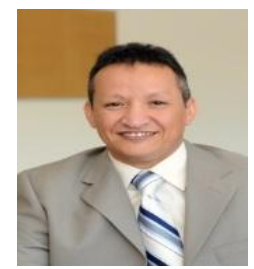

Mohmmed Bougataya received the B.Ing. in electrical engineering from USTO University, Oran, Algeria in 1998. He also received the M.Sc.A. and nd Ph.D. in electrical engineering from Université du Québec (UQTR) Québec, Canada in 2003 and 2010 respectively .

Mohammed worked as associate professor of electrical engineering at the Department of Computer Science and Engineering at the University of Quebec in CANADA since 2012 with 
interests in heat transfer mechanisms in biological tissues for thermal treatment practices, thermal mechanical stress in electronic packaging and rapid prototyping for electronic systems. His research contributions have been acknowledged by the scientific community and been used to write patent applications. He also has a considerable industrial R \& D experience between 2000 and 2010 with Hyperchip Inc and DreamWafer design group at TechnoCap Inc.

Dr Bougataya is the author/co-author of more than 80 scientific publications and research report.

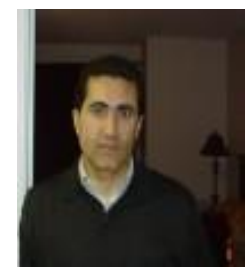

Karim El Guemhioui born in Tetuan, Morocco. He received a degree in civil engineering from École Mohammadia d'Ingénieurs (Morocco) in 1982. He earned a MS in computer science in 1992, and a PhD in computer science and engineering in 1997, both from the University of Connecticut, USA,

He worked several years as an engineer since 1982. He also worked for a couple of years at the Centre de Recherche en Informatique of Montréal (Canada) before becoming in 1998 a faculty member at the Université du Québec en Outaouais (Canada). His research interests include software engineering of distributed systems, model driven development, semantic web technologies, and bioinformatics.

Dr. El Guemhioui is a member of the Ordre des ingénieurs du Québec and a Fubright Alumnus.

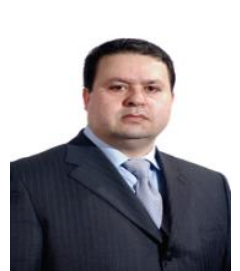

Ahmed Lakhssassi received the B.Ing. and M.Sc.A in electrical engineering from Université du Québec (UQTR), Québec, Canada in 1988 and 1990 respectively. He also received the Ph.D. in energy and material sciences in 1995 from INRS-Énergie et Matériaux Monteal, Québec, Canada. A year also, he had become a professor of electro-thermo-mechanical aspects at NSERC -Hydro-Quebec Industrial Research Chair at Electrical Engineering Department of the UQTR. Since 1998, he has been with UQO (Université du Québec en Outaouais), where he is currently titular professor and responsible of the LIMA laboratory LIMA (Advanced Microsystem Engineering Laboratory) developing algorithms for Microsystems thermo-mechanical monitoring and associated distributed sensors network. His research activities focus on the development of embedded algorithms for bio-implantable Microsystems, heat transfer mechanisms in biological tissues for thermal treatment practices. He is the author/co-author of more than 150 scientific publications and research report, and thesis advisor of 60 graduate and undergraduate students who completed their studies. Professeur Lakhssassi is a member of ReSMiQ, Nano-Québec, IEEE and OIQ. 